\title{
Du processus à Pékin au processus de Hohenheim : réseaux et coopération locaux et globaux
}

\author{
Editorial
}

Gudrun Lachenmann

\section{OpenEdition}

Journals

Édition électronique

URL : http://journals.openedition.org/apad/1091

DOI : 10.4000/apad.1091

ISSN : 1950-6929

Éditeur

LIT Verlag

Édition imprimée

Date de publication : 1 décembre 1995

Référence électronique

Gudrun Lachenmann, « Du processus à Pékin au processus de Hohenheim : réseaux et coopération locaux et globaux », Bulletin de l'APAD [En ligne], 10 | 1995, mis en ligne le 17 juillet 2007, consulté le 23 septembre 2020. URL : http://journals.openedition.org/apad/1091 ; DOI : https://doi.org/10.4000/ apad.1091

Ce document a été généré automatiquement le 23 septembre 2020.

Bulletin de l'APAD 


\title{
Du processus à Pékin au processus de Hohenheim : réseaux et coopération locaux et globaux
}

Editorial

\author{
Gudrun Lachenmann
}

Dans le dernier bulletin, le président de l'APAD, Jean-Pierre Olivier de Sardan, a souligné l'importance de "l'animation scientifique locale" avec comme instrument intéressant les "journées d'études, tables-rondes publiques, cycles de conférences" etc. Étant donné les processus de globalisation en cours, il est peut-être logique que cet instrument local soit automatiquement complété par l'instrument global, telles que les grandes conférences mondiales. Celle de Pékin, la conférence officielle des Nations Unies, comme le Forum des ONG, a démontré que des nouvelles formes de liaison entre le local et le global existent déjà, avec les femmes et la multiplication des arènes de concertation et des réseaux. Les femmes ont effectivement réussi à associer la recherche théorique, la politique (ou, comme elles le disent, l'activisme) avec les grass-roots (horribile dictu). Spécialement pour l'Afrique, cette intention est en bonne voie de se réaliser, au moins elle a été clairement formulée, et il semble que cette solidarité réclamée entre femmes intellectuelles, urbaines, des mouvements féministes, de la politique, des ONG, ainsi que les femmes rurales, très actives, est en train de se faire. Je lance donc un appel aux APADiens afin qu'ils se mettent un peu plus à jour et qu'ils tiennent comptent de la perspective de genre dans tous leurs travaux!

2 Pour moi, il s'est avéré (voir mon rapport sur le Forum de Pékin) une fois de plus absolument nécessaire de renforcer le débat public, critique, réflexif sur les processus de transformation en Afrique (et ailleurs), ce qui demande une certaine masse critique qui ne sera pas formée si les Universités africaines continuent à être démunies de ressources. Cela est un thème que j'ai l'habitude de soulever à toutes les occasions, souvent à l'étonnement de beaucoup de chercheurs et développeurs qui pensent que c'est au contraire l'enseignement de base qui doit être promu le plus possible (ce que je ne considère pas comme une alternative). Si ça n'est pas le cas, il s'établira un fossé ou 
dualisme profond, tel qu'il s'est présenté à Pékin contre ce qui semble être regardé comme les nouveaux fléaux de l'humanité, c'est à dire la "globalisation" et "l'ajustement structurel". Afin de sortir de cette impasse, nos travaux doivent permettre de sortir de cette confrontation infructueuse. Analyser et comprendre ce lien entre le global et le local doit donc devenir de plus en plus important à l'APAD.

Nous aurions souhaité que ce bulletin "entre deux conférences" soit l'instrument d'un tel processus de débat/formulation plus que cela n'a été le cas. Il se peut que ce soit un problème de langue, de langage théorique de la communauté chercheurs/ développeurs, qui en Allemagne, il est vrai, est surtout penché sur le monde anglophone. Au moins, en préparant ce Bulletin au Centre de Recherche sur le Développement, de la Faculté de Sociologie de Bielefeld, j'ai réussi à réunir une équipe mixte, avec Monika Salzbrunn juste revenue d'un stage d'études à l'EHESS de Paris, et Youssouf Diallo depuis déjà deux ans habitué à faire le lien entre les communautés scientifiques différentes, africaines, francophones, etc.

4 Pour commencer ce bulletin, nous avons choisi un article de Georg Elwert, professeur d'anthropologie sociale à l'Université Libre de Berlin, dont la version originale allemande date déjà de plusieurs années, bien avant que la confusion sur les questions d'identité, ethnicité etc. se soit présentée en Allemagne suite à la xénophobie ayant régné ici. Suit un article de Diallo portant sur sa recherche plus récente sur les éleveurs en Côte d'Ivoire - champ favori de beaucoup de projets de la coopération.

Un sujet beaucoup discuté dans le monde des développeurs en Allemagne concerne la décentralisation et le renforcement de l'administration locale, et le cas du Burkina Faso présenté et vécu par P.-J. Laurent prolonge ces réflexions de manière originale.

6 Enfin, ce bulletin se termine par un article sur la Côte d'Ivoire qui formule une demande très concrète à l'égard des sciences sociales, celle de faire comprendre les dynamiques sociales d'une société, non pas dans un but de pronostic, mais dans un but de réflexion et débat.

\section{AUTEUR}

\section{GUDRUN LACHENMANN}

University of Bielefeld, Sociology of development Research Centre, Postf. 100131, D-33501 Bielefeld, Allemagne. 